REVISTA ANDALUZA DE ANTROPOLOGÍA

NÚMERO 16: REFLEXIONES CONTEMPORÁNEAS SOBRE ABORDAJE DE LO RELIGIOSO, EL PATRIMONIO CULTURAL Y TURISMO RELIGIOSO

MARZO DE 2019

ISSN 2174-6796

[pp. 112-126]

http://dx.doi.org/10.12795/RAA.2019.i16.06

\title{
PÉREZ CEBADA, JUAN DIEGO (2014). Tierra devastada. Historia de la contaminación minera. Madrid: Síntesis; CHASTAGNARED, GERARD (2017). Humos y sangre. Protestas en la cuenca de las piritas y masacre en Rio Tinto (1877-1890). Alicante: Universidad de Alicante.
}

\section{Félix Talego Vázquez \\ Universidad de Sevilla}

Comentamos dos libros de mucha actualidad. Ambos estudian sociedades mineras y, en particular, la cuenca minera de Rio Tinto, territorio en el que se han dilucidado, desde la segunda mitad del siglo XIX, algunas de las cuestiones relevantes de la realidad socioambiental y política en Andalucía y en el Estado español, en especial en lo que refiere a la conformación de una economía de enclave minero. En ambos textos se aborda el conflicto ambiental conocido como "El Año de los Tiros", aunque en uno de ellos es el tema único (Humos y sangre) y en el otro (Tierra devastada) el punto de partida.

Llamamos "Año de los Tiros" a lo que en realidad fue un largo conflicto ambiental que se prolongó entre 1870 y 1890 y que tuvo uno de sus hechos decisivos en la masacre de más de doscientos civiles desarmamos, perpetrada por el ejército en Rio Tinto del 4 de febrero de 1888. No hubo depuración de responsabilidades ni investigación judicial, el crimen quedó impune, y un responsable principal de la masacre, el Gobernador Civil Bravo y Fuentes, continuó su carrera en la corrompida vida política de la Restauración. 
Tanto Pérez Cebada como Chastagnaret coinciden, aunque por caminos distintos, en que este conflicto ha sido el más decisivo en la historia de la cuenca minera onubense y contiene características que justifican su relevancia en la historia mundial de la minería industrial. Por eso, Gérard Chastagnaret, catedrático emérito e investigador vinculado a la Casa de Velázquez, ha querido quizá poner colofón a su larga y fructífera trayectoria de investigaciones sobre sociedades mineras con el estudio minucioso del conflicto que mantuvieron agricultores y compañías mineras entre 1870 y 1903 . Y Juan Diego Pérez, profesor titular en la Universidad de Huelva, no más llegar a la ciudad, se interesó por la historia minera de la provincia, intuyendo el "filón" investigador del "problema de los humos", como también era llamado en la prensa de la época. Y si Chastagnaret, tras estudiar otras cuencas mineras, decide concluir en "los humos" de Rio Tinto, Pérez Cebada, que comienza ahí, decide iniciar un largo periplo, un viaje investigador admirable, en el que, mediante estancias y becas en distintas universidades europeas y norteamericanas, durante catorce años, estudia los principales conflictos ambientales habidos en la minería no ferrosa entre 1850 y 1950. Ese viaje le permite demostrar -es esta una de las conclusiones sólidas de su libro- que el conflicto ambiental del Año de los Tiros figura entre los más relevantes en la historia de la minería industrial; y que ahondar en el conocimiento de lo ocurrido aquellos años en la cuenca de Rio Tinto puede aún enseñarnos mucho cara a los grandes conflictos ambientales del ciclo actual de fuerte incremento de la actividad minera.

Eran mujeres, hombres, niños, ancianos, campesinos, mineros, vecinos, acompañados por una banda de música. Procedían de todos los rincones de la cuenca minera onubense, que varios articulistas llamaban "el país de los Humos". Exigían mejoras en el trabajo y, simultáneamente, el fin de los humos (lluvia ácida, anhídrido sulfúrico), provocados por la calcinación al aire libre de piritas a una escala sin precedentes. Las peticiones que portaban fundían razones de lo que hoy llamamos justicia social y justicia ambiental: a las demandas por la mejora de las condiciones de trabajo se sumaban las de defensa de la salud de las poblaciones, de la agricultura y los animales. Esta síntesis constituye un ejemplo augural de ética ecológica en la geografía mundial. Y es paradigmática de otras muchas luchas que se han sucedido después en pro del cambio a una minería e industria sensibles a la explotación humana y de la naturaleza, pues una es necesariamente correlativa de la otra.

Hasta los años setenta del siglo XX la sociedad civil de la cuenca minera no volvería a movilizarse aglutinada por el derecho a un ambiente saludable -con mucho menos consenso y participación que en 1888-, pues durante las primeras décadas del siglo XX 
las huelgas mineras protestaron solo contra la injusticia laboral, y después se impuso la dictadura. Son cerca de cien años de olvido, pues los sucesos fueron orillados por autoridades, sindicalistas e historiadores, salvo algunas excepciones. No parece pues discutible la relevancia del estudio del "Año de los Tiros", por sí mismo, como lo hace Chastagnaret, o como episodio de partida de un viaje muy revelador por otros de los grandes conflictos ambientales de la minería mundial, como lo hace Pérez Cebada. Pero la oportunidad de estos libros es si cabe mayor, pues en la faja pirítica, de la que forma parte Rio Tinto, pero que llega hasta la ciudad de Sevilla (Mina Las Cruces) se está produciendo en los últimos años una remineralización, todavía bastante desantendida, que es correlativa a la que se da en la periferia europea, que sigue la ola de la remineralización extractivista en el Sur global desde la última década del siglo XX. No es descabellado pensar que Rio Tinto, y en general la faja pirítica andaluza (que se continúa en Portugal) pueden ser un "laboratorio" de la remineralización en Europa, tras varias décadas de descenso de la actividad minera. Algo así ha afirmado el Presidente de la Patronal minera AMINER en la inauguración del Salón de la Minería Metálica, celebrado en Sevilla en 2017: "La Junta de Andalucía, mediante su "Estrategia Minera de Andalucía 2020", posicionará a Andalucía como punto de encuentro de las industrias mineras de todo el mundo... las autoridades andaluzas han sacado a concurso más de mil derechos mineros de exploración, aumentando las probabilidades de que haya más yacimientos en un futuro no tan lejano"> (diario ABC, 17/10/2017). Lo mismo se desprende de la encuesta minera del Instituto Fraser ese mismo año, que clasificó a España como uno de los destinos de inversión minera más atractivos de Europa. O las declaraciones de 2019 de la multinacional canadiense Primary Energy Metals asegurando la buena posición de España para el suministro global de cobalto, cobre, níquel y vanadio, metales abundantes en la faja de sulfuros polimetálicos del suroeste penínsular (El Periódico, 8/1/2019).

No hay duda pues de que Tierra devastada y Humos y sangre son dos libros oportunos y actuales. Además, son intelectualmente relevantes, porque incorporan una perspectiva novedosa en el estudio de las sociedades mineras: el análisis de los problemas sociales y territoriales generados por los conflictos ecológicos de distribución y los pasivos ambientales de la actividad extractiva. Tanto Tierra devastada como Humos y sangre son libros bien construidos, con abundante información y con hipótesis que estimulan a continuar por "las vetas que explotan". Pero son distintos, por su foco de atención y por su perspectiva.

\section{Tierra devastada}

Como se ha dicho, Pérez Cebada inicia el viaje al fondo de la minería industrial en Rio Tinto, recala en relevantes conflictos europeos, pasa por las principales cuencas 
americanas, hasta adentrarse en algunos casos muy señalados en Japón. En su travesía recorre aproximadamente un siglo de minería no ferrosa, 1850-1950. Es un viaje a lo telúrico, al reino del azufre, ese "corazón de las tinieblas" que las mitologías de la antigüedad asociaban al inframundo. Un viaje que transforma al investigador, un poco también, inevitablemente, a la persona.

A lo largo de su periplo Juan Diego va haciéndose con las herramientas teóricas adecuadas para analizar lo que encuentra. Deducimos - no lo explicita- que las del materialismo histórico le parecen pobres para explicar los conflictos sociales que encuentra, porque esas lentes solo resaltan el conflicto capital-trabajo, y Juan Diego ve otras muchas tensiones, agrupamientos y tramas que no se ajustan a ese molde. La sociología y la historia convencional ha estado muy condicionada por la teoría de la "contradicción fundamental" de Capital y Trabajo, y sobrada de econometría, supuestamente, para "medir el crecimiento". Estos enfoques ven en las sociedades mineras sobre todo toneladas de mineral, ciclos de precios, número de puestos de trabajo, nivel de salarios, niveles de consumo y conflictos típicos de clase, en que los sindicatos mineros disputaban mejoras a la patronal o, en momentos álgidos de la lucha, incluso, la propiedad de los medios de producción y transformaciones políticas revolucionarias.

Pero en las páginas de Tierra devastada los obreros de la minería y sus organizaciones apenas aparecen. Esto puede causar en los lectores -así ha sido en nuestro caso- una perplejidad inicial: ¿por qué apenas aparecen los proletarios de las minas, si sabemos que en el periodo que Juan Diego estudia (1850-1950) se contaban por decenas de miles en las grandes cortas, desde Rio Tinto hasta Montana? ¿Los oculta conscientemente el autor? En absoluto: el rigor y la honestidad intelectual del Juan Diego son palpables página a página, llevándole justamente a resaltar la complejidad, la heterogeneidad de actores entre los que están los obreros- y la dimensión poliédrica de los conflictos, muy alejados de cualquier esquema maniqueo. La conclusión es clara: en los conflictos de distribución ecológica, aquellos en que se dilucidan los usos del territorio, los derechos de propiedad de comunidades, la salud de las personas, de las aguas, el aire, la vegetación y los animales, los obreros pocas veces se hacen notar, y cuando lo hacen, a menudo asumen posiciones similares a las de los empresarios mineros: comulgando con el extractivismo, incluso en los casos - muchos- en que era su propia salud e integridad física la primera perjudicada. La atenta mirada del autor le permite registrar algunas excepciones, y resaltar una entre todas: la alianza de los obreros con agricultores, ganaderos y vecinos que organizan la concentración en el Ayuntamiento de Rio Tinto el 4 de febrero de 1888. El viaje de Juan Diego por las principales cuencas mineras del mundo le permite demostrar que 
aquella alianza fue casi una excepción en la sucesión de conflictos en las grandes cuencas mineras, en las que los obreros, o se mantuvieron al margen, o se situaron del lado de los empresarios en la defensa a ultranza de la extracción, apoyando si al caso mejoras técnicas que paliaran o alejaran los efectos más aciagos de la contaminación. Pero sin cuestionar jamás que más extracción es mejor. Esto es lo que expresaba un periodista onubense en 1892:

"las empresas... obligaban a los obreros bajo la consabida amenaza [el despido] a firmar exposiciones a las cortes y a los poderes públicos en pro de la continuación de las calcinaciones, negando al par la insalubridad de las mismas." (Cornejo, 1892, en Pérez Cebada, 2014: 256).

En las minas galesas, los obreros aplaudían cuando los pleitos interpuestos por los agricultores y vecinos contra los humos favorecían a las empresas; en Butte (Montana) en la década de 1880, un momento tenso de la lucha de los agricultores contra Anaconda Cooper Mine, era célebre entre los obreros el dicho "no smoke, no wages for workingmen" (Pérez Cebada, 2014: 256). Son casos de chantaje a los obreros por parte de las compañías, pero el libro da cuenta también de casos de chantaje de las compañías a los poderes públicos utilizando el empleo como arma: así, Rio Tinto Company amenaza a las autoridades judiciales galesas con el traslado de parte de su fundición de Cwmafan a España y la consiguiente pérdida de puestos de trabajo (Pérez Cebada, 2014: 52). La conclusión del autor es clara: la capacidad de respuesta al dominio de las compañías mineras y a los problemas de polución que ocasionaban, disminuía en proporción directa a la dependencia laboral de las sociedades respecto a las compañías (Pérez Cebada, 2014: 86). Ante tal conclusión, el lector se pregunta: ¿Cuál ha sido la contribución neta del proletariado minero a la devastación del extractivismo cuprífero y sulfuroso?; ; cuándo y para qué fines el proletariado minero ha actuado realmente como antítesis del capital minero, cuándo y para qué fines ha sido un aliado, o un instrumento de ese capital? Volveremos sobre esta cuestión política y teórica clave cuando comentemos el libro de Chastagnaret.

Proseguimos los pasos de Pérez Cebada al interior del mundo minero industrial, y nos sorprende la profusión, lo abigarrado, complejo y enraizado de tantos conflictos que va mostrándonos: disputas, movilizaciones, informes científicos e interminables procesos judiciales se suceden en torno a los derechos de propiedad (a la propia noción y límites jurídicos de la propiedad), al derecho a preservar medios de vida y formas de vida tradicionales, de usos del suelo, a la salud pública, a la afectación de las cosechas, de los ganados, de las aguas de fuentes, abrevaderos y ríos. Intervienen en ellos actores 
muy diversos: empresas mineras, poderes locales e instancias gubernamentales (muchas veces desintonizados o incluso en discordia), agricultores, ganaderos, pescadores, vecinos preocupados por su salud, sindicatos mineros, ingenieros, comités de expertos que elaboran informes por encardo de gobiernos unas veces, de las empresas otras, y hasta de los vecinos afectados; científicos reputados a cuya palabra se otorga autoridad, dada la legitimidad del "saber científico"; médicos locales que atienden a diario enfermedades endémicas en las cuencas, pero también academias médicas, que pretenden zanjar la discusión sobre la inocuidad de los humos o las aguas ácidas y metálicas; políticos de profesión y periodistas, que medran, pero que no pocas veces asumen compromisos, lideran y contribuyen a elevar el debate.

La impresionante erudición que despliega el autor y su rigor analítico nos permiten captar la tremenda complejidad de estos conflictos, los juegos de alianzas, las "extrañas amistades". Podemos traer aquí tan solo algunas de las controversias y de los actores que las sostuvieron. Por ejemplo, una que hila el desarrollo temático del libro: el protagonismo en todos los casos del sector agrario, desde los hacendados a los campesinos y pastores. Juan Diego demuestra que fueron los agricultores los que mantuvieron el pulso más enérgico a las megaempresas mineras. En algunos casos, pero menos y con menor capacidad, los pescadores se organizaron también contra la gran minería, por las mismas razones que los agricultores: por el deterioro evidente de sus medios de vida causados por la contaminación. Pero son los agricultores los que desarrollan las organizaciones más sólidas y cuentan con más medios para sostener demandas judiciales; encuentran aliados entre los periodistas e incluyo contribuyen a sostener prensa local. Hay entre ellos elementos cultos que desarrollan hábiles retóricas que apelan a la tradición, la identidad, la salud, los derechos vecinales y comunales. Al respecto, son magníficas, de intensidad novelesca, las semblanzas de Ordóñez Rincón y Lorenzo Serrano en Rio Tinto, o la de Shozo Tanaka en Ashio, Japón. ¿ Fueron movilizaciones que hoy llamaríamos tipo NIMBY (no en mi patio trasero), motivadas egoístamente, para obtener compensaciones o retener el viejo poder oligárquico que las grandes compañías amenazaban? Juan Diego se interroga al respecto, ofreciendo una respuesta rica, matizada, pero afirmando a la postre que estuvo muy presente la resistencia al trastorno irreversible de unos usos sociales y culturales que, aunque con innegables injusticias, mantenían equilibrios y transacciones que las voladuras de la mina estaban haciendo saltar por los aires. Que, además, los afectados que se enfrentaron a las mineras, preocupados por la salud de las personas, las cosechas y los animales, desarrollaron una visión amplia de lo "medioambiental", que incluía ya la política, la sociedad y la cultura, tal y como lo desarrollaría el activismo 
ecologista posterior a los años sesenta del siglo XX. Una amplia visión que el autor no duda en sumar a los casos de "ecologismo popular" en los términos en que lo plantea Joan Martínez Alier (Pérez Cebada, 2014: 270-271).

La constatación del protagonismo de agricultores y en, segundo término, de pescadores en el enfrentamiento a la megaminería nos lleva de nuevo a la perplejidad: los agricultores y pescadores, que están casi desaparecidos de los estudios clásicos de las sociedades mineras tienen en el estudio de Juan Diego gran protagonismo, mientras que los proletarios, auténticos protagonistas en los estudios clásicos de las sociedades mineras, son aquí, en el mejor de los casos, "actores de reparto" -con la excepción, ya señalada, del giro sindical en febrero de 1888 en Rio Tinto liderado por Maximiliano Torner-. Concluimos por tanto que Tierra devastada no solo da rigurosa cuenta de daños a tierras y ríos, del trastorno profundo de sociedades locales, de tramas clientelares que alcanzan a los gobiernos, sino que sacude lugares comunes de la teoría social: en el período por él estudiado (1850-1950), en lo que refiere al pulso de la sociedad civil contra la devastación minera, fueron los agricultores los actores principales en el enfrentamiento con las multinacionales, mientras que el proletariado, con alguna excepción, queda en el papel de comparsa. Curiosa inversión de protagonismos, que debe alentar la reflexión teórica, porque el campesinado, los pequeños y medianos propietarios agrarios, han sido "la clase incómoda" ${ }^{1}$ en todos los estudios más o menos emparentados con el marxismo, tras la pesimista visión de ese sector que nos legó Marx, en especial en El dieciocho brumario de Luis Bonaparte, donde concluye que el campesinado carece de potencialidad revolucionaria. De ahí que, después, las corrientes principales del marxismo, teniendo por referente principal La cuestión agraria, de Kark Kautsky, y las políticas soviéticas, favorecieran el "final del campesinado" y su conversión en proletarios rurales centralizados en grandes granjas mecanizadas, o sumándolos al proletariado urbano (o minero). Porque el proletariado era, por seguir con el símil, "la clase cómoda" que venía preñada del futuro socialista.

¡Cuán diferente el panorama que ofrece Juan Diego! No ha debido serle fácil desechar las categorías marxistas (sensu lato), de tan larga y general aceptación en la Historia Económica. Que lo haya hecho avala su cualidad de investigador independiente, algo que puede pasar inadvertido a much@s, pero no a quienes sabemos de las presiones e inercias de las camarillas académicas. Recurre a otros filtros conceptuales. Efectivamente, ya en la introducción nos encontramos con otros referentes: John Muir, Aldo Leopold, Lewis

1. La clase incómoda, título del libro de Theodor Shanin (1983), anclado todavía en la maraña teórica del marxismo, pero crítico con las tesis ortodoxas de Karl Kautsky en La cuestión agraria 
Munford, Nicholas Georgescu-Roegen, Murray Bookchin, Ramachandra Guha, Joan Martínez Alier, y muchos otros que en esa línea han ido fortaleciendo la perspectiva de la Economía Ecológica y la Ecología Política. Es la mirada de los "conflictos ambientales" o "de distribución ecológica".

De sumo interés es también el seguimiento que Juan Diego hace a la polémica científica en los conflictos de contaminación minera. Encendido debate, de amplitud y profundidad sorprendentes, conectado con la evolución de los procedimientos técnicos de extracción y separación del mineral. Las teorías científicas inciden y, simultáneamente, se ven condicionadas por las soluciones técnicas adoptadas, que tienen que garantizar siempre la rentabilidad, intentando disminuir o desviar los efectos más perceptibles del daño ambiental. El debate científico en torno a los efectos de los humos y las aguas mineras estuvo atravesado por una polémica académica global, la de quienes sostenían la "teoría del daño invisible" sobre la salud y quienes sostenían el origen bacteriológico de las enfermedades. La preponderancia de esta última teoría a fines del XIX (Pasteur) restó fuerza a los estudios que ya ofrecían evidencias del influjo negativo de los metales y del azufre sobre la salud. También en el seguimiento de la polémica científica sobre los efectos de la polución minera las averiguaciones del autor escapan a cualquier esquematismo fácil, mostrándonos complejas líneas de fuerza en las que movilización social, políticas públicas, técnicas, precios del mineral, investigación, interaccionan condicionándose mútuamente. Aunque en ningún caso llegó a ponerse en cuestión la ideología que alimenta el extractivismo, estas tensiones condicionaron la evolución de los procedimientos mineros y la estructura de las compañías.

Muy revelador es también entender las razones de unos y otros actores en torno a la salud de las personas, en primer lugar, de los propios operarios. Fue un asunto central en todos y cada uno de los conflictos estudiados por Juan Diego, mostrando una vez más que las luchas contemporáneas contra megaproyectos, mineros o de infraestructuras, tienen precedentes interesantes que se remontan, en algunos casos a los años cuarenta del siglo XIX. La salud fue uno de los catalizadores de las posiciones de los actores. Asunto que, como sabemos, continúa muy presente en los conflictos que provoca el neoextractivismo (Martínez Alier, Walter, 2010), pero que, como demuestra Juan Diego, no es nuevo. Más aun, la lectura de Tierra devastada nos sorprende por la amplitud, profundidad y riqueza argumental con que fue abordada - y manipulada- la relación entre salud y polución, y nos convence de que los problemas de contaminación en la minería industrial han de estudiarse con perspectiva histórica, porque los conflictos de la "primera globalización minera" están pesando y pueden ayudar a esclarecer los presentes. 
En conclusión, el libro de Juan Diego debe contarse entre los referentes necesarios en una nueva literatura especializada que nos está ofreciendo otra mirada a la historia industrial contemporánea: una mirada que, cada vez con mayor solvencia y menos complejos, se hace extramuros de la cosmovisión productivista, aun hegemónica, si no en la academia, sí entre las corporaciones, los ministerios y una mayoría ciudadana educada en la ignorancia política.

\section{"Humos y sangre"}

El libro de Chastagnaret se centra exclusivamente en el conflicto provocado por la calcinación de las teleras (combustión al aire libre de los sulfuros para separar el cobre) en la cuenca minera de Rio Tinto, con minuciosidad y rigor: precedentes, hechos y consecuencias ambientales, sociales y políticas del problema de los humos (lluvia ácida). El autor explica en el prólogo las razones que le han llevado a escribir el libro tras una dilatada y fructífera trayectoria de investigaciones sobre cuestiones mineras. Lo hace, a nuestro juicio, con una afirmación demasiado rotunda: "Este libro hubiera debido haber sido escrito por otros y desde hace mucho tiempo" (Chastagnaret, 2017: 17). Es una afirmación en parte apropiada, en parte excesiva. Apropiada porque el crimen humano y ambiental de la minería en Huelva, cuyo episodio cardinal es la masacre del 4 de febrero de 1888, tiene suficiente trascendencia como para haber sido objeto de más atención. Confiemos que la creciente apertura teórica a los temas de la economía ecológica y la ecología política por parte de la academia favorezca tales estudios en un futuro próximo, de 1888 y de otros muchos conflictos ambientales de enorme envergadura que han venido sucediéndose, en la minería onubense y en otras cuencas.

Pero es a la vez excesiva, porque otros autores y autoras se han ocupado del tema antes, y con acierto, lo que él reconoce para el caso de las doctoras Ferrero (1999), Arenas (1999) y Peña (1998). Pero no para el estudio de Pérez Cebada antes reseñado, ni de otras publicaciones de este autor sobre el problema de los Humos en la cuenca minera onubense. Es una omisión que no se justifica, pues se trata del estudio que, según se ha explicado, asume de manera decidida el enfoque de la ecología política en el abordaje del conflicto entre "humistas" y "antihumistas". Enfoque al que se acerca Chastagnaret, aunque no lo reconozca ${ }^{2}$, pues la ecología política se caracteriza justamente porque, entre las múltiples miradas que son posibles en el estudio de los conflictos sociales, incorpora destacadamente la atención a los generados por la contaminación y el metabolismo

2. Extemporáneamente, en el prólogo declara: “... no practiqué militancia alguna y, en particular, esta investigación no entraña un compromiso ecologista. En este terreno mi única toma de partido está vinculada por mi interés por las abejas..." (Chastagnaret, 19) ¿? 
social implicado en la utilización de energía, extracción y diseminación de materiales. La perspectiva del autor está, en definitiva, próxima a estos enfoques novedosos, lo que deducimos por la perspectiva general, pero que él reconoce explícitamente: "el conflicto de los humos constituye un caso de laboratorio para el estudio de los conflictos socioambientales (Chastagnaret, 2017: 22).

Humos y sangre pretende responder a las siguientes cuestiones: cómo era y quien daba vida a la Liga Contra las Calcinaciones (Liga Antihumista) que se constituye años antes de los sucesos del cuatro de febrero de 1888, y cuáles fueron las modalidades y los temas de sus protestas; por qué durante años las quejas antihumistas se focalizaron en los daños sobre cultivos y ganados y no sobre salud pública; qué papel desempeñaron las relaciones clientelares y la colusión entre los poderes públicos y las empresas mineras; cómo se sucedieron los hechos que condujeron a la matanza y cómo procedieron los actores decisivos. A propósito de estos, el autor nos anuncia un tratamiento destacado de Maximiliano Torner, un anarquista cubano represaliado que había llegado a la cuenca algunos años antes. Sin embargo, no aporta informaciones nuevas especialmente reveladoras a lo que ya se conoce sobre este líder sindical. Y nos confirma algo que ya está perfectamente claro en el estudio referido de Pérez Cebada: que, aunque la intervención de Torner y la huelga de los mineros en las fechas inmediatas a los sucesos del 4 de febrero fue seguramente decisiva para la orquestación de la masacre por el Gobernador Civil y el Comandante del Regimiento de Pavía, fue la Liga Antihumista la protagonista determinante del envite contra las pretensiones de dominio absoluto de las compañías mineras en la cuenca. En la Liga desempeñaron papeles reseñables propietarios hacendados, como José María Ordóñez Rincón y José Lorenzo Serrano, pero sumó a muchos propietarios, ganaderos y campesinos, afectados todos por la lluvia ácida en sus cosechas y ganados. Chantagnaret va iluminando cada una de estas cuestiones y nos proporciona nuevos datos, merced a su riguroso examen de archivos locales, nacionales y de la Rio Tinto Company Limited ${ }^{3}$, la más poderosa entre las mineras que operaban en la comarca.

Otra cuestión relevante que pretende responder es cómo fue posible la alianza de la Liga y de los sindicatos, es decir el acuerdo entre el sector agrario (agricultores, ganaderos, hortelanos, campesinos) con el sector social de los proletarios mineros, en la organización y demandas de la manifestación del 4 de febrero de 1888. La explicación que aporta nos satisface y el relato del proceso es completo y coherente. Pero la sola lectura de su libro no nos hubiera permitido comprender la singularidad de esa alianza, incluso

3. Compañía fundadora de Rio Tinto Group, también hoy una de las grandes corporaciones mineras del mundo. 
la rareza histórica que supuso el entendimiento de operarios mineros y propietarios agrarios (seguidos por pequeños campesinos y aparceros). La mirada de Chastagnaret es, al respecto, demasiado local y demasiado circunscrita temporalmente, pues desdeña además ofrecer referencias y bibliografía sobre otros conflictos ambientales mineros que sin duda conoce. Sabemos por lo pronto -aunque son muchas las lagunas que restan por aclarar- que en la cuenca minera onubense esa alianza no ha vuelto a producirse, al menos en los decisivos términos de aquella ocasión: sector agrario y clase trabajadora unidos contra las empresas mineras, disputando sobre aquello que las compañías consideraban crítico para su estrategia: la continuidad, sin restricciones de cualquier tipo, de la calcinación al aire libre de los sulfuros polimetálicos. Es precisamente el libro comentado de Pérez Cebada el que nos proporciona la perspectiva adecuada para valorar la enorme significación que tuvo esa alianza de antihumistas y sindicalistas en 1888.

Son muchas las enseñanzas que se extraen de la lectura del libro de Chastagnaret, que invitan a seguir estudiando la minería en Huelva, sin duda una de las claves de la realidad del occidente andaluz y de la propia ciudad de Huelva. Pero de entre esas conclusiones queremos destacar una: la presencia ubicua del caciquismo y las relaciones clientelares, tejiendo una densa maya que garantizó complicidades, derramas y silencios desde las gentes que sufrían los gases azufrosos hasta la misma presidencia del gobierno, pasando, por supuesto por "La Compañía” (Rio Tinto Company) y el Gobierno Civil. Caciquismo que pudo proliferar sin dificultades en un marco político general de profundización en el doctrinarismo ultraliberal, dejando el campo abierto para la especulación y el dominio de las grandes empresas extranjeras que se constituyeron (Chastagnaret, 2017: 751754). El estudio amplio y sistemático de la documentación, mucha de ella privada, y de documentos militares que desconocíamos, ha permitido al autor destejer magistralmente esta sofisticada y asfixiante maya clientelar, y concluir con una afirmación rotunda: la masacre no fue causada por nerviosismo de la tropa o azarosos movimientos, sino premeditada, lo que permitió escribir al gobernador en su informe al Ministerio: "Lo ocurrido debe servir de escarmiento para lo venidero".

Pero todavía el autor, en su afán de albacea de las víctimas y de los protagonistas, encuentra otras razones, nada desdeñables, que contribuyeron al triunfo sin paliativos de los humistas y consagró el dominio total de la razón minera extractivista en la comarca. Afirma Chastagnaret: "Lo más extraño es que la corrupción no siempre era necesaria. La solidaridad intelectual y profesional, ... el culto beatífico, o primario, a un progreso cuyo contenido no se cuestionaba: todos esos elementos explicaban la indiferencia respecto a la primera actividad del país, la agricultura... Todo ello clarifica también la somera 
identificación entre depredación minera e industria, entre agricultura y retraso...". Sí, el culto beatífico al progreso, que se creía entonces que vendría de la mano del incremento de las magnitudes de extracción y de producción industrial. Es el mismo culto el que invocan, todavía hoy, las autoridades públicas y los portavoces de las corporaciones extractivas e industriales, aunque la palabra actual no es Progreso, sino Crecimiento. Clientelismo, corrupción y sometimiento florecieron al amparo de los valores del Progreso, de modo no muy distinto a como siguen extendiéndose hoy bajo el paraguas ideológico del "Crecimiento" (Economía, poder y megaproyectos, Megaproyectos en Andalucía).

Hay otra pregunta, fundamental, formulada al principio del texto, pero que atraviesa toda la obra: ¿Por qué las quejas antihumistas se dirigieron a los daños sobre cultivos y ganados y no sobre salud pública durante años?, (Chastagnaret, 2017: 62-63, 89). La salud, de las cosechas, las arboledas, las aguas y, por supuesto, de las personas, estuvo en el trasfondo de todo el contexto, y desde ellas, la salud de unos medios y unos modos de vida, incluso hasta la continuidad de un mundo. Pues en la perspectiva de las gentes de la comarca, como lo revelan las declaraciones abundantes de testigos y protagonistas que Chastagnaret ha rescatado del olvido para nosotr@s, era un mundo el que estaba desapareciendo y otro completamente diferente el que emergía. Así lo expresaba el Alcalde de Zalamea la Real en 1877:

"Es tal el incremento que va tomando la calcinación de minerales cobrizos en las Minas de Rio Tinto y Tharsis... que nos hace temer que llegue un día en que desaparezca toda vegetación en el radio a que alcancen los humos que se desprenden de esas calcinaciones.

Nuestro temor se funda en que, en el tiempo en que las de Rio Tinto eran explotadas por el Estado, solo existían en calcinación sobre 300 teleras a lo más, habiéndose destruido progresivamente grandes pinares,... y las huertas y demás fincas de particulares existentes en el término de dicha población... Hoy se calcinan sobre 2000 teleras, aumentando hasta llegar a 6000 según se dice. Con las dos mil existentes se nota ya la destrucción de sementeras y pastos... de donde hay que deducir forzosamente que será atacado también el arbolado y monte hasta quedar completamente infructífero, como lo está el término primitivo de las minas, llevando consigo la desaparición de la ganadería, colmenas y toda otra industria agrícola" (Chastagnaret, 2017: 78)

Y en 1878, los concejos de nueve municipios de la provincia, dirigían un escrito al ministro de Fomento. En él, tras mostrar la alarma por la destrucción de arboleda y 
sementeras, decían lo siguiente sobre la contaminación fluvial:

"las aguas que recogen en sus inmensos depósitos con destino al beneficio de los minerales, al salir de las balsas... se esparcen por nuestros campos, afluyendo a los arroyos y ríos, llevando inmensas cantidades de sales, cuyas bases son el cobre, el hierro, el arsénico, con las que envenenan su caudal, haciéndoles inútiles y hasta perniciosas para el abrevadero de ganadería y demás usos agrícolas" (Chastagnaret, 2017: 86)

Ciertamente, la memoria y el vínculo con los paisajes, con los medios y los modos de vida es un factor relevante en los conflictos ambientales, como lo fue el que se estudia en Humos y Sangre. La alarma de aquellas gentes ante el trastorno abrupto de todo lo que conocían, pudo ser una de los catalizadores en la organización de los antihumistas y el tesón que desplegaron, más allá de la afectación de intereses económicos, que, sin duda, contaron también.

Abordaremos finalmente "la cuestión obrera", que nos permite enlazar con el análisis anterior del libro de Pérez Cebada. La suma de ambos textos permite conocer bien cuál fue la conducta de los operarios de las compañías en el conflicto ambiental de los humos. Chastagnaret, aunque con información más abundante y prolija que Pérez Cebada, coincide en lo fundamental con él: la capacidad de respuesta al dominio de las compañías disminuía en proporción directa a la dependencia laboral de las sociedades respecto a las mismas. A lo largo del texto lo evidencia de varias maneras: Rio Tinto y Nerva, los municipios más "minerizados" (el término es nuestro) fueron los que se negaron hasta última hora a prohibir la calcinación al aire libre, cuando ya todos los municipios afectados lo habían hecho. Esa circunstancia decidió la manifestación del 4 de febrero de 1888 (Chastagnaret, 2017: 338, 344-345). Alosno y Calañas, a pesar de tener en sus términos importantes minas, no llegaron a caer totalmente bajo el dominio de las mineras, si bien, los intereses de las compañías se hicieron sentir en ellos en distintos momentos, porque las empresas amenazaban con despidos y utilizaban testaferros en los Ayuntamientos (Chastagnaret, 2017: 332-333, 366-379). Los pueblos menos dependientes del empleo de las mineras elevaron quejas al Ministerio para que se aplicase el Decreto Albareda, que el gobierno había aprobado pocos días después de la masacre de 1888 y que establecía la disminución progresiva de las calcinaciones hasta su desaparición total en 1890. Sin embargo, el Ayuntamiento de Rio Tinto, "el principal vasallo municipal" de la Rio Tinto Company estuvo reclamando hasta el final la suspensión de dicho decreto (Chastagnaret, 2017: 344-345). 
En un apartado de título elocuente, "En caso de apuro: el arma del despido", el autor nos proporciona un preciso relato de la instrumentación de los obreros por las compañías para forzar la abolición del "Decreto Albareda":

“...la segunda fase de reducción de las calcinaciones entró en vigor el 1 de enero de 1890. El 3, Riotinto [la Compañía] hizo como si hubiera obedecido despidiendo a doscientos obreros. Estos constituyeron una comisión inmediatamente recibida en Huelva por Sundheim, administrador de la compañía... Rio Tinto $<<$ fabricó $>>$ parados para utilizarlos como arietes contra el decreto...el gobernador, con un gran sentido de la oportunidad, dejó que una manifestación llegara hasta Huelva. (Chastagnaret, 2017: 359-361).

En definitiva, hay coincidencia de Chastagnaret, para el caso específico de la cuenca onubense, y de Pérez Cebada, para esta y otras de las principales cuencas cupríferas: ambos nos muestran a unos obreros y cuadros medios coercibles y maleables por las mega compañías mineras; ambos señalan que los obreros han sido el actor social más dependiente y frágil de las sociedades mineras. El "arma del despido", lo que hoy solemos llamar "el chantaje de los puestos de trabajo", fue por lo general eficaz para doblegar y, en ciertos extremos, instrumentalizar al grueso de los empleados a los intereses de las compañías mineras. Sin embargo, es casi un lugar común en la tradición de los "estudios sociales" (los que en un sentido más o menos genérico se inspiran en las creencias básicas del marxismo) que los operarios de la minería, en especial la "clase obrera" minera, en Rio Tinto como en las principales cuencas mineras del mundo, ha sido muchas veces vanguardia de insurrección al capital, foco de idearios impugnadores y revolucionarios. ¿No se cuentan los sindicatos mineros entre los más tempranos, mejor organizados, de luchas más airosas y sacrificadas de toda la historia del movimiento obrero? No hay que dudar que ha sido así: tanta literatura sociológica e historiográfica no puede haber sido un espejismo. Y no han podido errar su instinto literario tantos escritores que nos han dejado páginas memorables sobre el sacrificio y la épica de los operarios en las minas, desde Germinal, obra maestra de Zola, El intruso, de Blasco Ibáñez, El tungsteno, de César Vallejo, El metal de los muertos, de Concha Espina, o Los jinetes del alba, de Jesús Fernández Santos. ¿No figuran las heroicas huelgas de 1913 y 1920 en Rio Tinto (Pérez López, 2007), el levantamiento de los mineros de Asturias en 1934 o las huelgas y movilizaciones de los mineros británicos en los ochenta contra las políticas neoliberales 
de Thatcher entre los testimonios señeros de la lucha del proletrariado?; ¿acaso no recibieron generales muestras de solidaridad los mineros de Aznalcóllar encerrados en la catedral de Sevilla cuando cerró la mina tras la rotura en 1998 de la balsa de lodos que envenenó las riberas del río Guadiamar hasta Doñana?¿no ha entrado en Madrid en 2012, arropada por la multitud, la "marcha negra" de los mineros del carbón?

¿Con qué versión nos quedamos? Es una disyuntiva fundamental, y no es tanto empírica -de si hubo más o menos confrontación y de sus contenidos- como teórica -del significado y alcance de esa confrontación. La teoría marxista, de poderoso influjo a todo lo ancho de las ciencias sociales, ha llevado a creer a generaciones de investigadores que la confrontación por mejoras salariales y de condiciones de desempeño laboral era una cuestión trascendente, es decir, una cuestión en la que se dilucidaba el proceso histórico de avance social. La tradición republicanista (Pettit, Skinner, de Francisco) nunca aceptó esta máxima. La nueva mirada sobre los hechos a que nos invita la Ecología Política parece apuntar en esta misma dirección. El material que nos ofrecen los dos magníficos libros que hemos comentado es insuficiente para hacer una afirmación tan principal y categórica. Queremos simplemente invitar a seguir repensando, porque detectamos, tanto en estos libros como en otros estudios de Ecología Política, cierta renuencia en responder sin complejos a una cuestión clave: ¿qué contribución neta ha tenido y está teniendo la llamada clase obrera en los conflictos ambientales, reconocidos ahora como los conflictos más trascendentes?

\section{Bibliografía}

Arenas, C.: Empresa, mercados, mina y mineros. Riotinto, 1873-1936, Universidad de Huelva-Fundación Rio Tinto, 1999.

Ferrero, M. D.: Capitalismo minero y resistencia rural en el suroeste andaluz: Rio Ttinto, 1873-1900, Universidad de Huelva, 1999.

Peña, M. A.: Clientelismo político y poderes periféricos durante la Restauración (18741923), Universidad de Huelva, 1998.

Pérez López, J. M.: Sindicalismo minero en Huelva. La huelga de 1913 en Rio Tinto, Huelva, Cuenca Minera de Río Tinto, 2007.

Shanin, T.: La clase incómoda, Madrid, Alianza, 1983. 